\title{
Source parameters for the 2013-2015 earthquake sequence in Nógrád county, Hungary
}

\author{
Zoltán Wéber
}

This is the accepted manuscript of the paper published in

Journal of Seismology 20(3), 987-999, doi: 10.1007/s10950-016-9576-6

The final publication is available at link.springer.com

\begin{abstract}
Between 2013 June and 2015 January, 35 earthquakes with local magnitude $M_{L}$ ranging from 1.1 to 4.2 occurred in Nógrád county, Hungary. This earthquake sequence represents above average seismic activity in the region and is the first one that was recorded by a significant number of three-component digital seismographs in the county. Using a Bayesian multiple-event location algorithm, we have estimated the hypocenters of 30 earthquakes with $M_{L} \geq 1.5$. The events occurred in two small regions of a few squared kilometers: one to the east of Érsekvadkert and the other at Iliny. The uncertainty of the epicenters is about 1.5$1.7 \mathrm{~km}$ in the E-W direction and $1.8-2.1 \mathrm{~km}$ in the N-S direction at the $95 \%$ confidence level. The estimated event depths are confined to the upper $3 \mathrm{~km}$ of the crust. We have successfully estimated the full moment tensors of $4 M_{w} \geq 3.6$ earthquakes using a probabilistic waveform inversion procedure. The non-double-couple components of the retrieved moment tensor solutions are statistically insignificant. The negligible amount of the isotropic component implies the tectonic nature of the investigated events. All of the analyzed earthquakes have strike-slip mechanism with either right-lateral slip on an approximately N-S striking, or leftlateral movement on a roughly E-W striking nodal plane. The orientations of the obtained focal mechanisms are in good agreement with the main stress pattern published for the epicentral region. Both the $\mathrm{P}$ and $\mathrm{T}$ principal axes are horizontal, and the $\mathrm{P}$ axis is oriented along a NE-SW direction.
\end{abstract}

Keywords Earthquake location - Earthquake focal mechanism - Earthquake moment tensor - Bayesian inversion · Waveform inversion - Tectonic stress

\section{Z. Wéber}

Kövesligethy Radó Seismological Observatory, MTA CSFK GGI, Meredek u.18., H-1112 Budapest, Hungary

E-mail: weber@seismology.hu

\section{Introduction}

Between 2013 June and 2015 January, unusual seismic activity took place in Nógrád county, Hungary. During this 20-month long time period, 35 earthquakes with local magnitude $M_{L}$ ranging from 1.1 to 4.2 were recorded in the region. There were 2 events with $M_{L}>4,7$ with $3 \leq M_{L}<4$, 14 with $2 \leq M_{L}<3$ and 12 with $1 \leq M_{L}<2$. The two largest earthquakes were strongly felt in the epicentral regions, where they caused minor damage. They were felt even in the capital city of Budapest. In both cases, the macroseismic intensity was as large as 6 on the European Macroseismic Scale. Some of the $M_{L}>3$ events were also felt in the epicentral areas.

In Hungary (the central part of the Pannonian basin), seismic activity can be characterized as moderate. The seismicity pattern shows that earthquakes are restricted to the upper part of the crust and the epicenters are distributed all around the country (Fig. 1). However, there are certain areas where seismicity is higher and where significant, destructive earthquakes with magnitude $M>5$ occurred in the last centuries (Zsíros, 2000).

Nógrád county (Fig. 1) does not belong to the most seismically active areas in Hungary. The first known earthquake in the region occurred in 1834 and before 2013, only 20 events were observed with magnitude $M \geq 2$. More specifically, in this time period there were 2 events with $M>4$ (Cserhátsurány, 1930, $M=4.2$; Borsosberény, 1951, $M=$ 4.7), 7 with $3 \leq M<4$ and 11 with $2 \leq M<3$. These numbers illustrate that the 2013-2015 earthquake sequence studied in this paper represents above average seismic activity in the Nógrád region.

Recently, the Hungarian National Seismological Network (HNSN) has undergone a great deal of modernization and extension. While in 2006 it consisted of only 6 broadband stations, there were 1 short-period and 11 broadband 


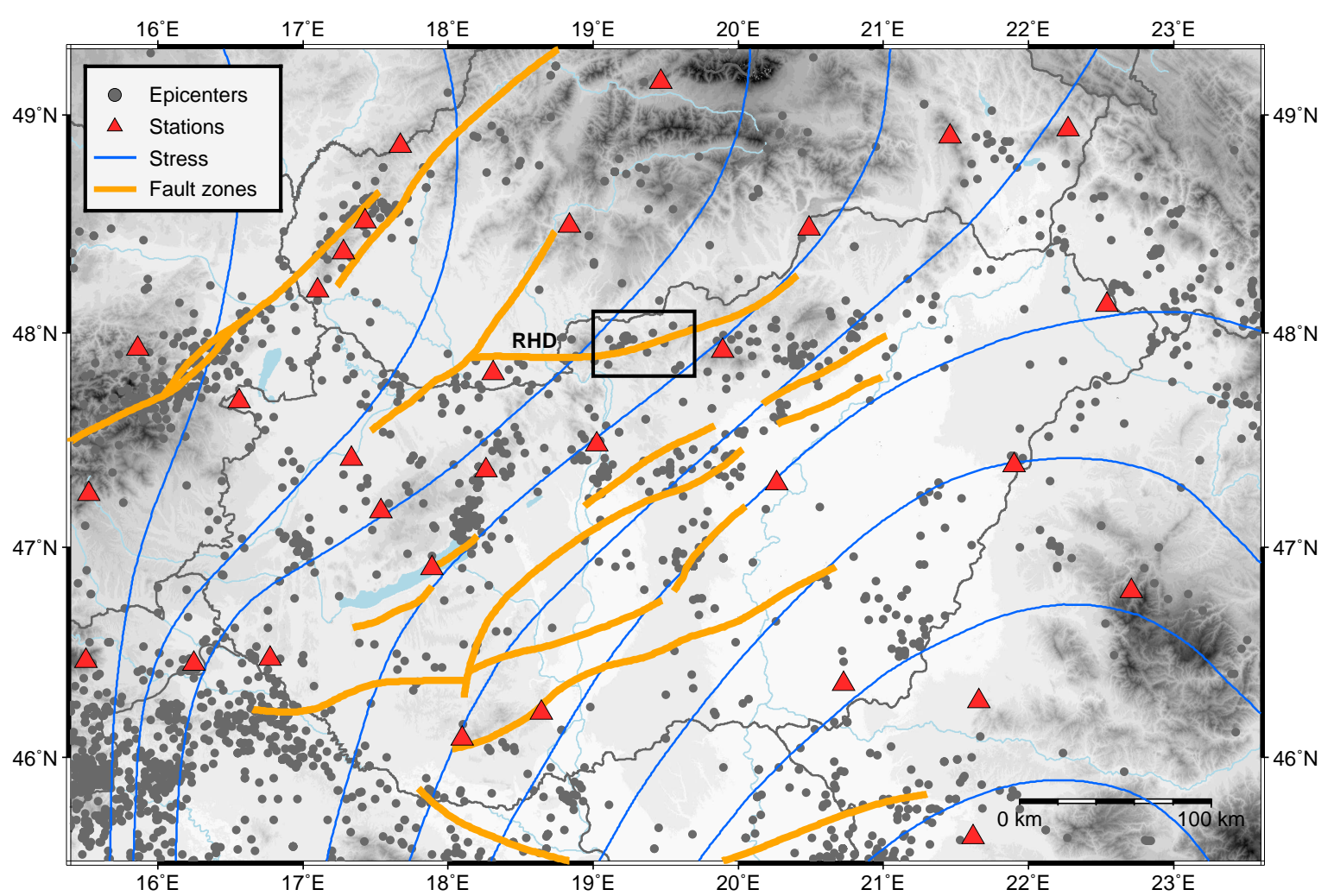

Fig. 1 Seismicity of Hungary and its surroundings for the period of 1900-2013 (gray dots). Only earthquakes with magnitude above 2 are shown. Red triangles denote the location of the seismic stations used in this study. The black rectangle encircles the Nógrád region where the earthquake sequence studied in this paper occurred. Thin blue lines depict the trajectories of maximum horizontal stress directions after Bada et al. (2007), whereas thick orange lines indicate main active fault zones after Horváth et al. (2006). RHD: Rába-Hurbanovo-Diósjenó line

ones operating around the country in 2013. By the end of 2014 , the number of the broadband stations increased to 13. The 2013-2015 earthquake sequence is, therefore, the first one that was recorded by a significant number of threecomponent digital seismographs in the Nógrád region. This provides a good opportunity to study earthquake sources in an area where we have little knowledge about fault parameters and small-scale tectonic structure.

In this paper we analyze all seismic data available to us for the 2013-2015 Nógrád sequence in order to determine the hypocenter locations of the events applying a Bayesian multiple-event location algorithm and estimate the source mechanisms (full moment tensors) of the largest events using a probabilistic waveform inversion procedure. Reliable knowledge of earthquake source properties is essential to better understand the present-day tectonic processes characteristic to the source area.

\section{Data}

The waveform data used in this study were mainly recorded by the HNSN operated by the Kövesligethy Radó Seismological Observatory (KRSO) (Fig. 1). At the beginning of the Nógrád earthquake sequence, the HNSN comprised 11 permanent broadband stations and 1 short-period station. By the end of 2014, the number of the broadband stations reached 13. The broadband stations were equipped with Streckeisen STS-2 or STS-2.5 and Guralp CMG-3T seismometers with natural period of $120 \mathrm{~s}$. The only shortperiod station used three-component Kinemetrics SS-1 sensors with natural frequency of $1 \mathrm{~Hz}$. Seismological data from the neighboring countries and international agencies were also available. Seismograms from the Slovak National Seismic Network (SNSN) were essential for the research presented in this paper.

\section{Hypocenter location}

The largest earthquakes of the Nógrád sequence were well recorded on seismic stations across Hungary, and also across eastern and central Europe. Events with $M_{L}>2.5$ were also detected by most stations in Hungary and Slovakia. The smallest epicentral distance was about 35-40 kilometers.

We manually picked $\mathrm{P}$-wave arrival times from verticalcomponent seismograms and $\mathrm{S}$-wave arrival times from horizontal-component waveforms where possible. For esti- 
mating hypocentral locations, we considered those events only that had at least $4 \mathrm{P}$-wave and $4 \mathrm{~S}$-wave time readings. Data from seismic stations with epicentral distance greater than about $300 \mathrm{~km}$ were not taken into account in the localization procedure. After applying these selection criteria, we found $30 M_{L} \geq 1.5$ earthquakes with the desired number of high-quality arrival time data. Altogether, we collected $169 \mathrm{Pg}, 220 \mathrm{Pn}, 172 \mathrm{Sg}$, and $20 \mathrm{Sn}$ (581 in total) arrivals recorded at 35 stations.

To determine the locations of the Nógrád events, we used the Bayesloc multiple-event location algorithm (Myers et al., 2007, 2009). Multiple-event methods consist of simultaneously inverting arrival times for many events to determine both event locations and a set of travel time corrections. They can generate high-quality locations, and identify and remove outlier data. This latter peculiarity of multipleevent locators is very useful since outliers can significantly bias the results of single-event algorithms.

Bayesloc approaches the location problem as a hierarchy with three model components: the travel-time model, the arrival-time model, and the prior model. Each model component is treated as a conditional probability that can be combined into a joint posterior probability distribution (PPD) using Bayes' theorem. Bayesloc generates realizations of the various model parameters from the joint PPD using Markov Chain Monte Carlo (MCMC) sampling. For full description of the algorithm, the reader should refer to the original papers (Myers et al., 2007, 2009). Here we provide only a brief description of the method.

The travel-time model allows for corrections to modelbased predictions. The corrections consist of adjustment to the slope of the travel time curve and static corrections for each station, event, phase, event-phase pairs and stationphase pairs. These terms tend toward zero unless data suggest otherwise. In this study we used only station-phase corrections accounting for small-scale heterogeneities around the recording stations not included in our simple velocity model.

The arrival-time model accounts for errors in the measured arrival time after travel-time corrections have been applied. A priori arrival-time errors are assumed Gaussian with zero mean and variance determined by a precision (1/variance) term that can be factored into a number of elements, including phase, station, and event precisions. Each precision factor has the effect of up-weighting data that has low variance and down-weighting data with higher variance. For our data set, we found that only the arrival-time error phase precision factor is resolved well enough to use in this study.

Bayesloc also incorporates stochastic phase labels to account for phase misidentification by the analyst. Finally, the origin prior model allows the user to provide constraints for the epicenter, depth, or origin time for any of the events that may be known. In this study, we used the bulletin locations
Table 1 The 1D earth model used in this study.

\begin{tabular}{cccc}
\hline $\begin{array}{c}h \\
(\mathrm{~km})\end{array}$ & $\begin{array}{c}v_{P} \\
(\mathrm{~km} / \mathrm{s})\end{array}$ & $\begin{array}{c}v_{S} \\
(\mathrm{~km} / \mathrm{s})\end{array}$ & $\begin{array}{c}\rho \\
\left(\mathrm{g} / \mathrm{cm}^{3}\right)\end{array}$ \\
\hline 0 & 5.30 & 3.05 & 2.76 \\
3 & 5.74 & 3.30 & 2.85 \\
19 & 6.29 & 3.61 & 2.96 \\
26 & 7.93 & 4.56 & 3.29 \\
\hline
\end{tabular}

Layer depths $(h), \mathrm{P}$-wave velocities $\left(v_{P}\right)$ and $\mathrm{S}$-wave velocities $\left(v_{S}\right)$ are after Gráczer and Wéber (2012). For density $\rho$, an empirical law is used: $\rho=1.7+0.2 v_{P}$, where $\rho$ is measured in $\mathrm{g} / \mathrm{cm}^{3}$ and $v_{P}$ in $\mathrm{km} / \mathrm{s}$.

as starting positions for the MCMC sampling but placed non-informative priors on the event origins (hypocenters and origin times).

The Bayesloc joint PPD for the Nógrád earthquakes was determined using eight Markov chains. The results presented in this paper were drawn from the last 10,000 of 20,000 MCMC samples for each chain, that is we used the first $50 \%$ of the iterations as a burn-in period to reduce the influence of starting positions with little prior information. Our one-dimensional (1D) velocity model (Table 1) was developed from arrival-time data of earthquakes and controlled explosions for the territory of Hungary (Gráczer and Wéber, 2012). Travel-time curves were calculated from the velocity model using the TauP toolkit (Crotwell et al., 1999).

The retrieved station-phase corrections are mostly close to zero. Values greater than $0.5 \mathrm{~s}$ (about $15 \%$ of the available station-phase pairs) are well constrained with tight confidence. After station-phase corrections, the $\mathrm{P}$ phases are most precisely fit and given the heaviest weights in the arrivaltime model, with average values of 22.7 and 10.8 for $\mathrm{Pg}$ and $\mathrm{Pn}$, respectively, whereas $\mathrm{Sg}$ and $\mathrm{Sn}$ arrivals have mean weights of 7.1 and 0.5 . These numbers indicate the importance of the P-wave arrival data of the close stations in the final results whereas $S n$ phases do not contribute significantly to the solutions. This result is consistent with the common experience that first arrivals (Pg and Pn), which do not arrive in the coda of earlier phases, are more precisely picked than later arrivals.

MCMC sampling also includes testing alternate phase labels for each arrival datum. The phase labels that increase overall probability are more likely to be accepted. Our results show that more than $96 \%$ of the input phase labels agree with the a posteriori ones with posterior probability greater than 0.9 . There are 12 arrivals ( $2 \%$ of the data) where the most probable phase name a posteriori is not equal to the input phase label. Among these 12 arrivals, 4 input Pg arrivals are relabeled as $\mathrm{Pn}$ and 7 input Pn arrivals as Pg. Only one input phase is relabeled as an outlier. The above results suggest that input phase labels are correct, with high confidence, in approximately $96 \%$ of the instances for our data set. 

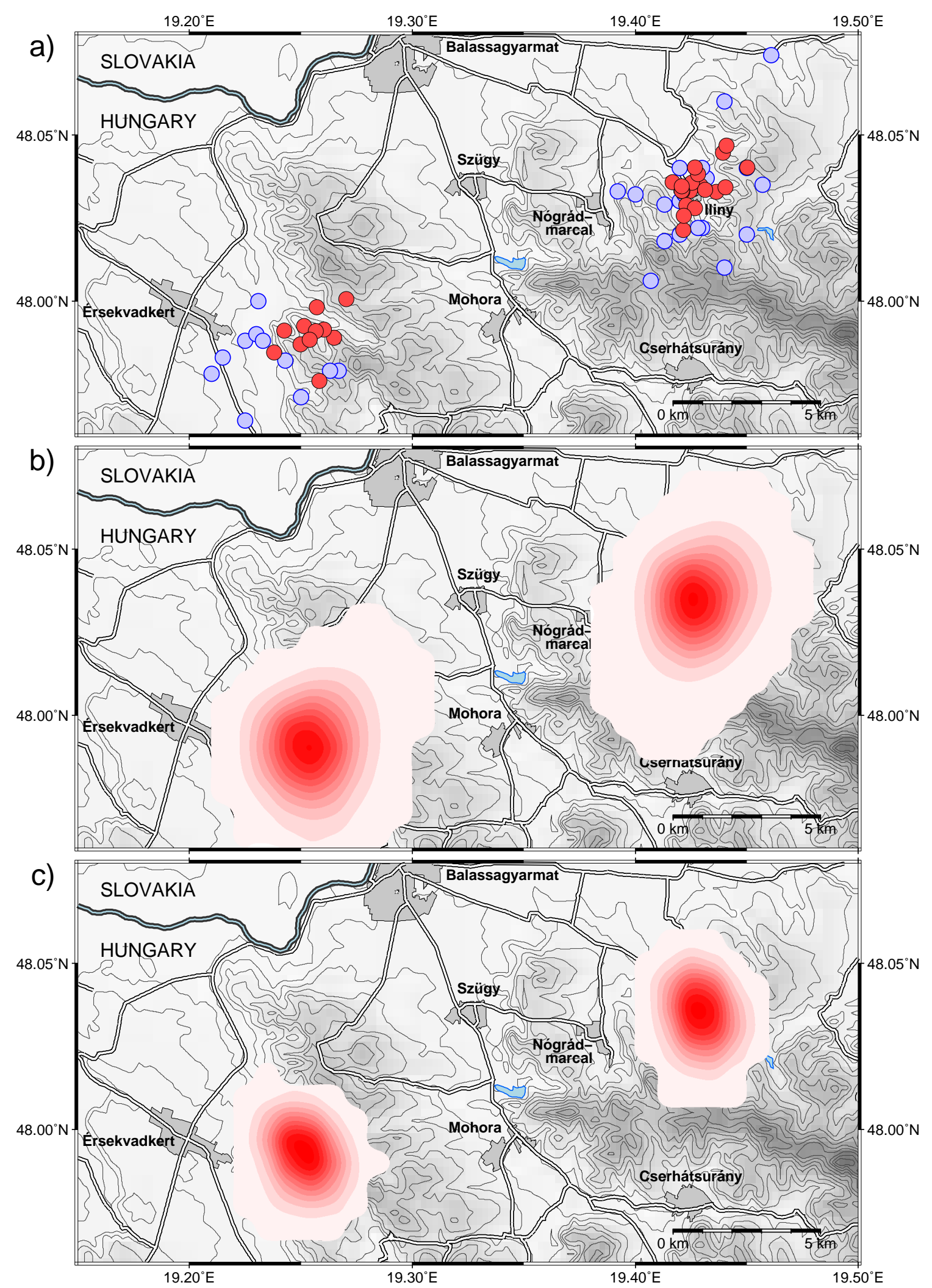

Fig. 2 Epicenters for the 2013-2015 earthquake sequence in Nógrád county. a) Blue circles denote the bulletin locations whereas red circles represent the epicenters determined in this study using the Bayesloc multiple-event locator. $b$ ) Joint posterior probability distribution (PPD) of the events normalized for the two epicentral regions separately. c) PPD for the two $M_{L}>4$ earthquakes: event 1 near Érsekvadkert and event 12 at Iliny. For event numbers see Table 2. 
Table 2 Hypocentral parameters for the 2013-2015 earthquake sequence in Nógrád county together with their 95\% confidence intervals.

\begin{tabular}{|c|c|c|c|c|c|c|}
\hline $\begin{array}{c}\text { Event } \\
\text { No. }\end{array}$ & $\begin{array}{c}\text { Date } \\
\text { (yyyy-mm-dd) }\end{array}$ & $\begin{array}{c}\text { Time } \\
\text { (hh:mm:ss) }\end{array}$ & $\begin{array}{l}\text { Longitude } \\
\left({ }^{\circ} \mathrm{E}\right)\end{array}$ & $\begin{array}{c}\text { Latitude } \\
\left({ }^{\circ} \mathrm{N}\right)\end{array}$ & $\begin{array}{l}\text { Depth } \\
(\mathrm{km})\end{array}$ & $M_{L}$ \\
\hline 1 & 2013-06-05 & $18: 45: 46$ & $19.251_{-1.6}^{+1.6}$ & $47.992_{-1.9}^{+1.8}$ & $2.0_{-1.7}^{+0.9}$ & 4.1 \\
\hline 2 & 2013-06-05 & $20: 46: 38$ & $19.270_{-1.6}^{+1.6}$ & $48.001_{-2.2}^{+2.0}$ & $2.1_{-1.8}^{+0.9}$ & 1.7 \\
\hline 3 & 2013-06-05 & $22: 00: 56$ & $19.258_{-1.6}^{+1.8}$ & $47.976_{-2.6}^{+3.1}$ & $1.5_{-1.4}^{+1.4}$ & 1.5 \\
\hline 4 & 2013-06-11 & $05: 31: 26$ & $19.238_{-1.6}^{+1.6}$ & $47.985_{-2.1}^{+2.0}$ & $1.0_{-0.9}^{+1.7}$ & 2.3 \\
\hline 5 & 2013-06-14 & $06: 35: 53$ & $19.265_{-2.1}^{+2.6}$ & $47.989_{-2.8}^{+3.7}$ & $1.2_{-1.2}^{+1.6}$ & 1.5 \\
\hline 6 & 2013-06-16 & $15: 10: 27$ & $19.260_{-1.7}^{+1.7}$ & $47.991_{-2.2}^{+2.1}$ & $1.6_{-1.5}^{+1.3}$ & 2.0 \\
\hline 7 & $2013-06-23$ & $03: 47: 21$ & $19.242_{-1.6}^{+1.6}$ & $47.991_{-2.0}^{+1.8}$ & $1.3_{-1.3}^{+1.6}$ & 2.3 \\
\hline 8 & $2013-06-23$ & $15: 47: 53$ & $19.257_{-1.7}^{+1.7}$ & $47.991_{-2.2}^{+2.1}$ & $1.3_{-1.3}^{+1.6}$ & 2.1 \\
\hline 9 & 2013-07-02 & 19:07:32 & $19.250_{-1.6}^{+1.6}$ & $47.987_{-1.9}^{+1.8}$ & $1.6_{-1.5}^{+1.4}$ & 3.4 \\
\hline 10 & $2013-07-02$ & $19: 47: 01$ & $19.254_{-1.7}^{+1.7}$ & $47.988_{-2.0}^{+1.9}$ & $1.1_{-1.0}^{+1.7}$ & 2.3 \\
\hline 11 & $2014-01-17$ & $04: 22: 36$ & $19.422_{-2.0}^{+1.9}$ & $48.021_{-3.0}^{+2.8}$ & $1.4_{-1.3}^{+1.5}$ & 1.7 \\
\hline 12 & 2014-01-19 & $01: 34: 34$ & $19.429_{-1.4}^{+1.5}$ & $48.035_{-2.0}^{+1.8}$ & $2.0_{-1.7}^{+1.0}$ & 4.2 \\
\hline 13 & 2014-01-19 & 01:48:43 & $19.425_{-1.4}^{+1.5}$ & $48.033_{-2.0}^{+1.8}$ & $1.4_{-1.4}^{+1.5}$ & 3.2 \\
\hline 14 & 2014-01-19 & $16: 40: 47$ & $19.450_{-1.5}^{+1.5}$ & $48.040_{-2.0}^{+1.8}$ & $1.5_{-1.4}^{+1.4}$ & 2.2 \\
\hline 15 & 2014-01-21 & 01:06:05 & $19.425_{-1.5}^{+1.6}$ & $48.036_{-2.0}^{+1.9}$ & $1.2_{-1.1}^{+1.6}$ & 2.7 \\
\hline 16 & $2014-01-22$ & $12: 13: 43$ & $19.417_{-1.5}^{+1.6}$ & $48.036_{-2.0}^{+1.9}$ & $1.6_{-1.5}^{+1.3}$ & 2.9 \\
\hline 17 & $2014-01-22$ & $12: 49: 48$ & $19.421_{-2.3}^{+2.6}$ & $48.033_{-3.4}^{+3.6}$ & $1.6_{-1.5}^{+1.4}$ & 1.6 \\
\hline 18 & 2014-02-03 & $23: 57: 07$ & $19.439_{-1.5}^{+1.6}$ & $48.045_{-2.1}^{+1.9}$ & $1.8_{-1.6}^{+1.2}$ & 2.0 \\
\hline 19 & 2014-02-19 & $15: 54: 25$ & $19.257_{-1.6}^{+1.7}$ & $47.998_{-1.9}^{+1.8}$ & $1.1_{-1.1}^{+1.7}$ & 2.5 \\
\hline 20 & 2014-08-03 & 01:10:24 & $19.436_{-1.4}^{+1.5}$ & $48.033_{-2.0}^{+1.8}$ & $1.2_{-1.1}^{+1.6}$ & 2.1 \\
\hline 21 & 2014-08-03 & 01:48:06 & $19.423_{-1.5}^{+1.5}$ & $48.029_{-1.9}^{+1.8}$ & $1.7_{-1.6}^{+1.2}$ & 3.0 \\
\hline 22 & 2015-01-01 & $06: 43: 23$ & $19.431_{-1.5}^{+1.5}$ & $48.033_{-2.0}^{+1.9}$ & $1.2_{-1.1}^{+1.6}$ & 3.9 \\
\hline 23 & 2015-01-01 & $10: 27: 44$ & $19.427_{-1.5}^{+1.5}$ & $48.028_{-2.1}^{+1.9}$ & $1.0_{-1.0}^{+1.7}$ & 2.1 \\
\hline 24 & 2015-01-01 & $10: 45: 57$ & $19.422_{-1.5}^{+1.5}$ & $48.026_{-1.9}^{+1.9}$ & $1.7_{-1.5}^{+1.2}$ & 3.9 \\
\hline 25 & 2015-01-01 & $10: 46: 38$ & $19.428_{-1.7}^{+1.7}$ & $48.038_{-2.1}^{+1.9}$ & $2.0_{-1.8}^{+1.0}$ & 3.5 \\
\hline 26 & 2015-01-01 & $14: 22: 09$ & $19.421_{-1.5}^{+1.5}$ & $48.033_{-2.0}^{+1.9}$ & $1.5_{-1.4}^{+1.4}$ & 3.1 \\
\hline 27 & 2015-01-01 & 17:00:53 & $19.427_{-1.7}^{+1.7}$ & $48.040_{-2.2}^{+2.1}$ & $1.4_{-1.3}^{+1.5}$ & 1.7 \\
\hline 28 & 2015-01-01 & 19:44:36 & $19.421_{-1.5}^{+1.5}$ & $48.035_{-2.0}^{+1.8}$ & $1.2_{-1.2}^{+1.6}$ & 2.8 \\
\hline 29 & $2015-01-02$ & 01:44:02 & $19.440_{-1.6}^{+1.6}$ & $48.034_{-2.0}^{+1.9}$ & $1.4_{-1.3}^{+1.5}$ & 1.8 \\
\hline 30 & 2015-01-07 & $13: 48: 53$ & $19.441_{-1.7}^{+1.7}$ & $48.047_{-2.4}^{+2.3}$ & $1.6_{-1.5}^{+1.3}$ & 2.1 \\
\hline
\end{tabular}

Confidence intervals for longitude and latitude are given in $\mathrm{km} ; M_{L}$ : local magnitude.

The hypocentral parameters obtained for the Nógrád earthquakes are summarized in Table 2 and Fig. 2. The table shows and Fig. $2 \mathrm{c}$ illustrates that the resulting epicenters are better constrained in the E-W direction than in the N-S. For most of the analyzed events, the radius of the $95 \%$ confidence zones varies between 1.5 and $1.7 \mathrm{~km}$ in the E-W, and between 1.8 and $2.1 \mathrm{~km}$ in the N-S direction (Table 2). The estimated event depths are confined to the upper $3 \mathrm{~km}$ of the earth crust. The retrieved depth uncertainties are rather large since in our data set the smallest epicentral distance is much greater than the event depth.

Fig. 2a shows the epicenters obtained in this study together with the bulletin locations, whereas Fig. $2 b$ depicts the joint PPD of the events. The earthquakes occurred in two distinct epicentral zones: one to the east of Érsekvadkert and the other at Iliny. Epicenters estimated by routine observatory data processing show high scatter, whereas our solutions are confined to small regions of a few squared kilometers. Inside the two regions, event distribution does not 
show any particular trend (Fig. 2b). Considering the size of the resulting epicentral confidence zones, we can safely conclude that the 11 earthquakes near Érsekvadkert and the 19 events at Iliny occurred in their respective small-scale seismogenic zones.

\section{Source mechanisms}

In this section we estimate the source mechanisms (full moment tensors) of four Nógrád earthquakes with local magnitude $M_{L} \geq 3.4$. We first briefly summarize the probabilistic non-linear waveform inversion procedure that we applied on the available broadband seismograms. Then we analyze the selected events in detail and discuss the obtained moment tensor solutions.

\subsection{Waveform inversion method}

In this study we used the probabilistic non-linear waveform inversion method of Wéber $(2006,2009)$ to retrieve the focal mechanisms of the investigated earthquakes. It has already been successfully applied for estimating the full moment tensor of both local and near-regional events in the Pannonian basin (Wéber and Süle, 2014; Wéber, 2016). Here we provide a brief description of the method, but for full details the reader is referred to Wéber $(2006,2016)$.

The procedure works in the point-source approximation. We describe a general seismic point source by six independent moment tensor rate functions (MTRFs) allowing the moment tensor to vary arbitrarily as a function of time. If the velocity structure and the event location are known, there is a linear connection between the seismograms and the MTRFs. Basically, the MTRFs are obtained by deconvolving the station specific Green's functions (GFs) from the observed seismograms. For constructing the synthetic GFs, we employed a propagator matrix-wavenumber integration method (Wang and Herrmann, 1980; Herrmann and Wang, 1985; Herrmann, 2013), which allows us to calculate the entire wavefield for horizontally layered earth structures. In this study, we used the same 1D velocity model as that used for earthquake localization (Table 1).

The waveform inversion procedure applied in this study consists of the following main steps (Fig. 3).

Step 1: The hypocenter of the event is estimated from observed arrival times by a method that provides both the hypocentral coordinates and their uncertainties. Here we used the Bayesloc multiple-event locator (Myers et al., 2007, 2009).

Step 2: Because source mislocation can significantly bias the results of any moment tensor inversion procedure, we should further refine the hypocentral coordinates using

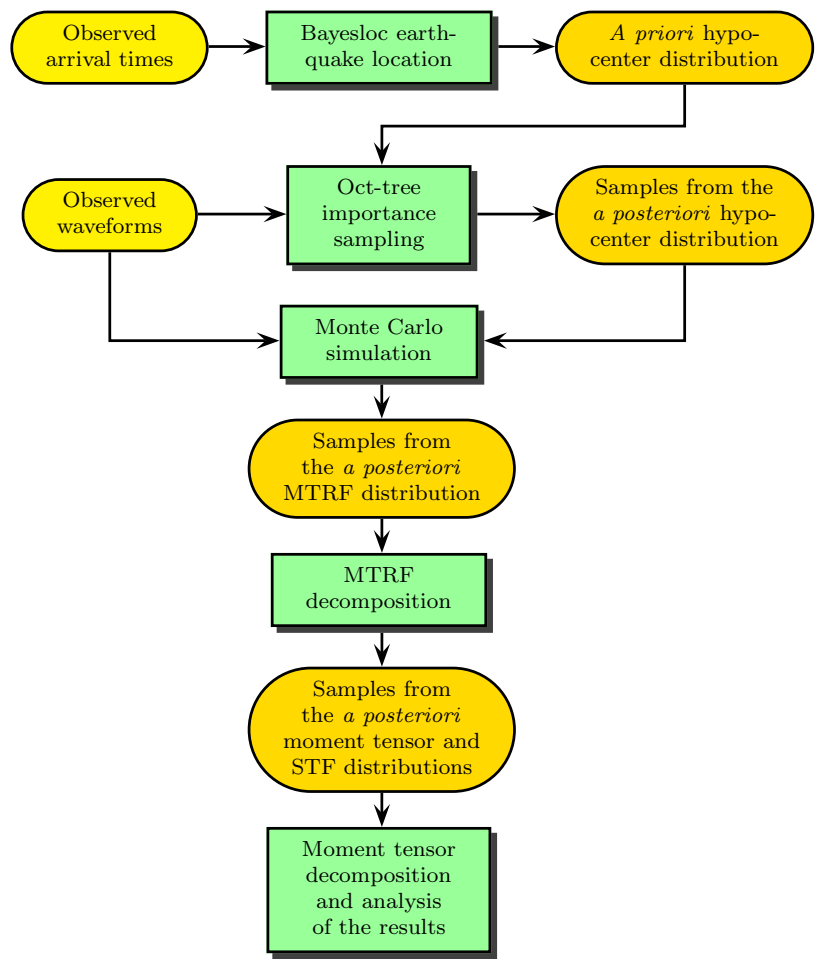

Fig. 3 Flow diagram of the probabilistic waveform inversion algorithm used in this study.

waveform data. Therefore, we consider the hypocenter distribution estimated in Step 1 as a priori information and perform a Bayesian inverse calculation to improve the hypocentral location. For mapping the PPD of the hypocenters, we apply the oct-tree importance sampling algorithm developed by Lomax and Curtis (2001). As a result, we get a large number of points that are samples from the PPD of the hypocenter. For all these samples, the MTRFs are also calculated. Their distribution represents the uncertainty of the MTRFs due to that of the source location.

Step 3: Measurement errors and modeling errors also lead to MTRF uncertainty even for a fixed source position. To estimate the overall uncertainties of the retrieved MTRFs, we use a Monte Carlo simulation technique (Rubinstein and Kroese, 2008). The goal of Monte Carlo simulation is to determine how random variation in the input data affects the uncertainty of the output. In our problem, source location and seismograms represent the input data, whereas MTRFs are the output. In the course of the simulation, we generate many new realizations of input data sets by randomly generating new hypocenters and waveforms according to their respective distributions. Then each generated input data set is inverted for MTRFs. The distribution of the obtained set of solutions approximates well the PPD of the MTRFs.

After having mapped the PPD of the source location in the previous step, generating a random hypocenter for the Monte Carlo simulation is straightforward. For generating 
individual realizations of noisy seismograms, we first calculate the waveform residual corresponding to the best MTRF solution obtained in Step 2. We consider this residual as a realization of the measurement and modeling errors. Convolving this error sample with a uniform white noise yields a sample of simulated error: it differs from the original sample of error but has the same amplitude spectrum. Then, we add the simulated error to the observed seismograms and obtain a new realization of waveforms which we invert for the MTRFs. In this study, we performed 10,000 Monte Carlo simulations and thus generated 10,000 MTRFs according to the a posteriori distribution.

Step 4: Assuming that the focal mechanism is constant in time, the previously obtained MTRFs are decomposed into a time-invariant moment tensor and a source time function (STF). The problem is non-linear and is solved by an iterative $L_{1}$ norm minimization technique (Wéber, 2009). To allow only forward slip during the rupture process, we impose a positivity constraint on the STF. After the decomposition of the MTRFs, a large number (actually 10,000 in this study) of moment tensor and STF solutions are obtained that can be considered as samples from their respective PPDs. The final estimates are given by the maximum likelihood points.

Step 5: Once the moment tensors are retrieved, their principal axes are deduced. Then each moment tensor is decomposed into a double-couple (DC), a compensated linear vector dipole (CLVD) and an isotropic (ISO) part (Jost and Herrmann, 1989). Finally, the distributions of the retrieved source parameters are displayed as histogram plots.

The above described procedure can also be used when the STF is assumed to be known. In that case, Monte Carlo simulation directly results in samples from the PPD of the moment tensor.

In this study, the method of Riedesel and Jordan (1989) is employed to display the moment tensor solution. The principal vectors of a moment tensor define the tension $(\mathrm{T})$, neutral $(\mathrm{N})$, and compression $(\mathrm{P})$ axes, while the principal values give their magnitudes. Here we adopted the convention of Sipkin (1993) that the $\mathrm{P}$ and T axes always point upwards and the principal axes form a right-handed coordinate system. In the principal axis system, various unit vectors can be constructed using various linear combinations of the principal vectors: $\mathbf{m}$ describes a general source mechanism, $\mathbf{d}$ represents a DC mechanism, $\mathbf{i}$ corresponds to a purely isotropic source, and $\mathbf{l}_{\mathbf{1}}$ and $\mathbf{l}_{\mathbf{2}}$ define two possible CLVD vectors. The density plot (2D histogram) of the $\mathbf{m}$ vector, together with the $\mathbf{d}, \mathbf{i}$, and $\mathbf{l}_{\mathbf{1}, \mathbf{2}}$ vectors corresponding to the best moment tensor solution are then plotted on the surface of the focal sphere. The great circle connecting the $\mathbf{d}$ and $\mathbf{l}_{\mathbf{1 , 2}}$ vectors on the unit sphere denotes the locus of deviatoric sources. The distribution of the density plot of $\mathbf{m}$ with respect to the $\mathbf{d}, \mathbf{i}$, and $\mathbf{l}_{\mathbf{1}, 2}$ vectors informs us on the statistical significance of the DC, ISO, and CLVD components of the solution.

\subsection{Moment tensor solutions}

To reliably recover earthquake focal mechanisms by waveform inversion, it is necessary to use seismograms with high enough signal-to-noise ratio (SNR) observed by a station network with good azimuthal coverage. Focal mechanisms can be resolved even for small-magnitude events if the source-receiver distances are small and, as a result, the SNR of the observed waveforms is not less than 2 in the inversion frequency band. Moreover, low-magnitude local events have to be analyzed at high frequencies $(>0.5 \mathrm{~Hz})$ where the waveforms may be strongly affected by small-scale heterogeneities of the medium not included in our simple 1D velocity model. So to calculate reasonably accurate GFs for inverting low-magnitude events, the path-length of the modeled seismic waves should be kept at a minimum. Summing up, short-period waveform inversion may be successful only if the seismograms to be inverted are recorded at short epicentral distances (Wéber, 2016).

Unfortunately, for the Nógrád earthquake sequence the source-receiver distances are not short enough to invert small-magnitude events with high-frequency waveforms. At the same time, for 6 events with $M_{L} \geq 3.4$, signal energy at long periods is sufficient to use long-period seismograms in the waveform inversion. Among these 6 events, however, 2 earthquakes (events 24 and 25 in Table 2) occurred within only 41 seconds, making the recorded seismograms unusable for further analysis. As a result, there remain 4 earthquakes (events 1, 9, 12 and 22) suitable for waveform inversion to estimate their source mechanisms.

For estimating the full moment tensors of the selected events, we used seismograms recorded at broadband stations operating in Hungary and the surrounding countries (Fig. 1). The stations and components were manually selected based on the SNR in the inversion frequency band. Both the observed displacement waveforms and the GFs were band-pass filtered with a Butterworth filter with cut-off frequencies of 0.05 and $0.125 \mathrm{~Hz}$ (corner periods of 20 and $8 \mathrm{~s}$, respectively). The processed time window started at $5 \mathrm{~s}$ before the arrival of the first P-phase and its length was varied between 30 and $100 \mathrm{~s}$ depending on the epicentral distance. The synthetic waveforms (GFs) were windowed in the same way as the observed ones. Our 1D velocity model is not accurate enough to predict the observed arrival times, so to obtain the optimal correlation between the synthetics and the data, before inversion we applied a time shift between them. We allowed different time shifts for the P-phase and the S-phase.

Since the inversion frequency band is well below the corner frequency of the investigated events, we assumed that the STF was a known parameter and it had a 4-second triangular shape. When the STF is considered as a known parameter, the Monte Carlo simulation described in the previous sec- 


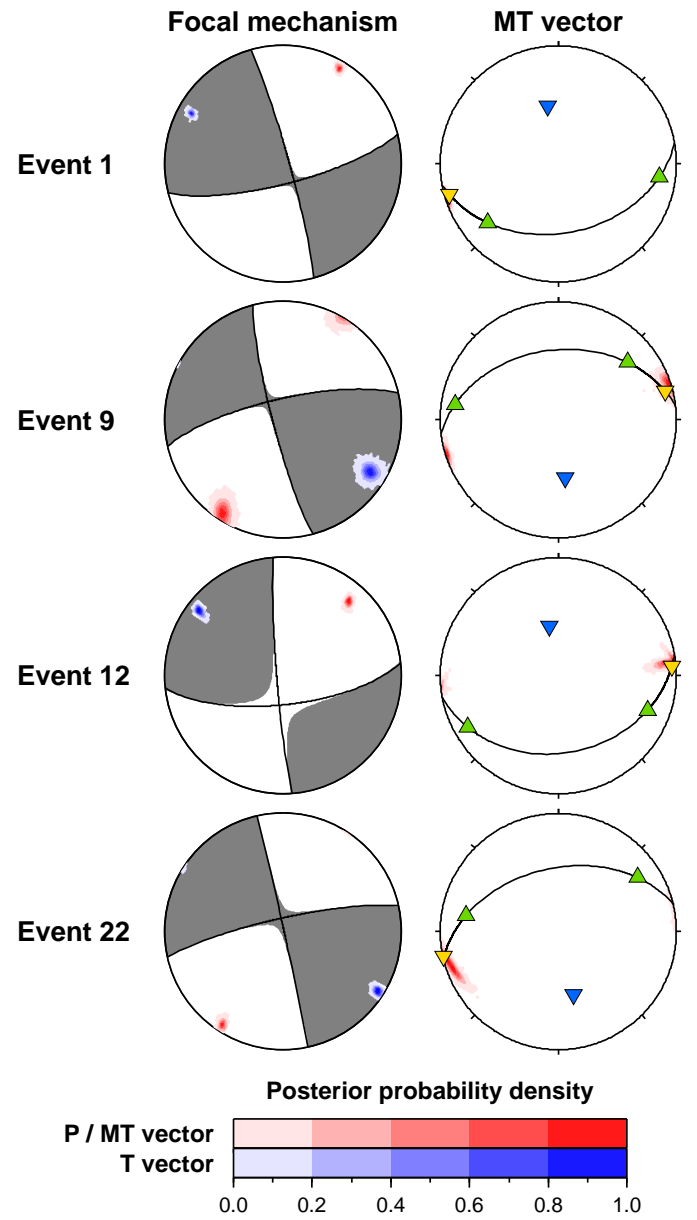

Fig. 4 Source mechanisms and density plots of the moment tensors (MTs) obtained for the 4 analyzed earthquakes using waveform inversion. The beach balls represent the deviatoric part of the mechanisms (shaded area: compression; open area: dilatation). The density plots of the $\mathrm{P}$ (red) and $\mathrm{T}$ (blue) principal axes are plotted on top of the beach balls. For displaying the MT vector, the method of Riedesel and Jordan (1989) is employed (orange inverse triangle: d vector for the DC component; green triangles: $\mathbf{l}_{\mathbf{1}, \mathbf{2}}$ vectors for the CLVD components; blue inverse triangle: $\mathbf{i}$ vector for the isotropic part). The great circle connecting the $\mathbf{d}$ and $\mathbf{l}_{\mathbf{1 , 2}}$ vectors defines pure deviatoric mechanisms. Equal area projection of lower hemisphere is used. Event numbers refer to those in Table 2.

tion directly results in samples from the posterior moment tensor distribution.

The waveform inversion results for the investigated events are listed in Table 3 and plotted in Fig. 4. The figure shows the beach ball representation of the deviatoric part of the full moment tensor solutions together with the density plots (2D histograms) of the $\mathrm{P}$ and $\mathrm{T}$ principal axes. In addition, the density plots of the resulting full moment tensors are also illustrated. The scalar seismic moments and principal axes of the maximum likelihood mechanisms are presented in Table 4 together with their $95 \%$ confidence intervals.
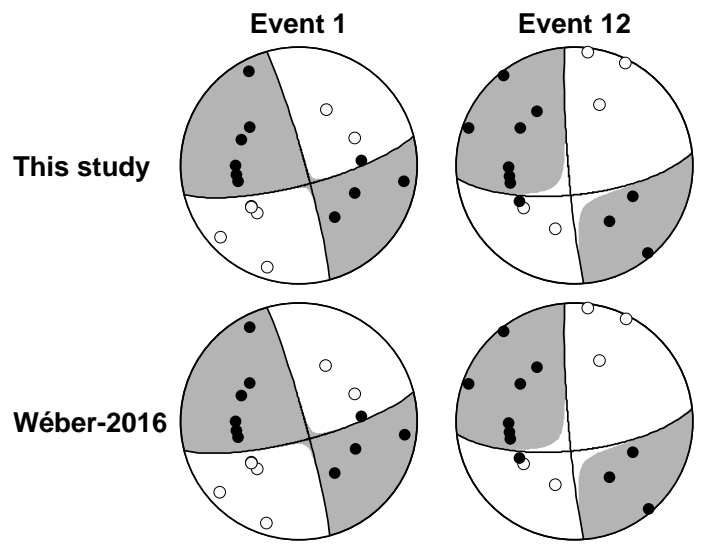

USGS NEIC

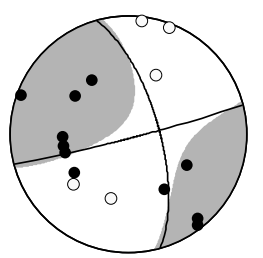

GFZ

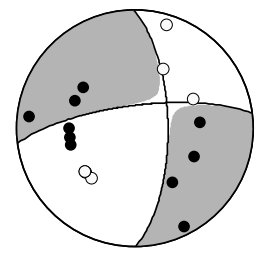

Fig. 5 Comparison of the moment tensor solutions obtained in this study with those reported by the USGS NEIC, GFZ and Wéber (2016) for the analyzed $M_{L}>4$ earthquakes. Only deviatoric components are shown (shaded area: compression; open area: dilatation). First-arrival $\mathrm{P}$-wave polarities are indicated as well (solid circle: compression; open circle: dilatation). Equal area projection of lower hemisphere is used. Event numbers refer to those in Table 2.

According to Fig. 4 and Table 4, both the $\mathrm{P}$ and $\mathrm{T}$ axes are strongly clustered around well defined directions. For event 9 , the weakest earthquake analyzed in this study, the density plots of the principal axes are somewhat less well constrained. Nevertheless, the plots suggest that the moment tensor solutions are robust and of sufficient quality to allow further tectonic interpretation.

Table 3 shows that the DC component varies between 84 and 95\%, and the CLVD and ISO components are below $10 \%$. Indeed, the DC vector lies within the density plot of the moment tensor for all the investigated earthquakes (Fig. 4) suggesting that the non-DC components are statistically insignificant and pure DC mechanisms can be considered as the solutions for the events.

The two $M_{L}>4$ earthquakes investigated here (events 1 and 12) were also analyzed by Wéber (2016) using the same waveform inversion method. However, the prior hypocenters he used in his inverse calculations differ from those applied in this study. It may be interesting to see how sensitive our waveform inversion method is to the $a$ priori hypocenter location. Moreover, in the on-line catalogs of the U.S. 
Table 3 Maximum likelihood centroids, source mechanisms, and moment magnitudes $\left(M_{w}\right)$ determined by waveform inversion.

\begin{tabular}{rcccccccccccc}
\hline $\begin{array}{c}\text { Event } \\
\text { No. }\end{array}$ & $M_{w}$ & $\begin{array}{c}\text { Lon. } \\
\left({ }^{\circ} \mathrm{E}\right)\end{array}$ & $\begin{array}{c}\text { Lat. } \\
\left({ }^{\circ} \mathrm{N}\right)\end{array}$ & $\begin{array}{c}\text { Depth } \\
(\mathrm{km})\end{array}$ & $\begin{array}{c}\text { Strike } \\
\left({ }^{\circ}\right)\end{array}$ & $\begin{array}{c}\text { Dip } \\
\left({ }^{\circ}\right)\end{array}$ & $\begin{array}{c}\text { Rake } \\
\left({ }^{\circ}\right)\end{array}$ & $\begin{array}{c}\text { DC } \\
(\%)\end{array}$ & $\begin{array}{c}C L V D \\
(\%)\end{array}$ & $\begin{array}{c}\text { ISO } \\
(\%)\end{array}$ & $\mu$ & Author \\
\hline 1 & 4.0 & 19.246 & 47.982 & 3 & $76 / 345$ & $76 / 86$ & $5 / 166$ & 94 & 1 & 5 & - & \\
& 4.0 & 19.248 & 47.972 & 3 & $76 / 345$ & $77 / 86$ & $4 / 167$ & 93 & 2 & 5 & 0.01 & Wéber $(2016)$ \\
& 3.9 & 19.240 & 47.970 & 10 & $263 / 360$ & $74 / 67$ & $-23 /-162$ & 96 & 4 & - & 0.36 & GFZ \\
9 & 3.6 & 19.235 & 47.984 & 2 & $165 / 257$ & $83 / 76$ & $165 / 7$ & 95 & 1 & 4 & - & \\
12 & 4.2 & 19.428 & 48.031 & 5 & $175 / 84$ & $86 / 70$ & $-160 /-4$ & 84 & 8 & 8 & - & \\
& 4.2 & 19.429 & 48.031 & 5 & $175 / 84$ & $86 / 70$ & $-160 /-4$ & 84 & 8 & 8 & 0.00 & Wéber (2016) \\
& 4.0 & 19.348 & 48.053 & 4 & $344 / 75$ & $69 / 87$ & $177 / 21$ & 65 & 35 & - & 0.28 & USGS NEIC \\
\hline
\end{tabular}

Solutions reported by other authors are also indicated. To measure the difference between our solutions and those published elsewhere, the parameter $\mu$ defined by Pasyanos et al. (1996) is used. For values of $\mu<0.25$, the focal mechanisms are essentially the same, but start to diverge for $0.25<\mu<0.50$. Moment magnitudes are calculated according to the definition of Hanks and Kanamori (1979). Event numbers refer to those in Table 2.

Table 4 Scalar moments and principal axes of the investigated earthquakes together with their $95 \%$ confidence intervals.

\begin{tabular}{rccccccc}
\hline Event & $M_{0}$ & \multicolumn{2}{c}{ T axis } & \multicolumn{2}{c}{$\mathrm{N}$ axis } & \multicolumn{2}{c}{ P axis } \\
No. & $(\mathrm{Nm})$ & azimuth $\left(^{\circ}\right)$ & plunge $\left(^{\circ}\right)$ & azimuth $\left(^{\circ}\right)$ & plunge $\left(^{\circ}\right)$ & azimuth $\left(^{\circ}\right)$ & plunge $\left(^{\circ}\right)$ \\
\hline 1 & $9.643_{-0.997}^{+1.246} \times 10^{14}$ & $119_{-3}^{+2}$ & $-13_{-4}^{+4}$ & $327_{-15}^{+14}$ & $-75_{-5}^{+6}$ & $211_{-2}^{+2}$ & $-7_{-5}^{+4}$ \\
9 & $3.144_{-0.513}^{+1.729} \times 10^{14}$ & $300_{-6}^{+6}$ & $-15_{-10}^{+11}$ & $140_{-76}^{+27}$ & $-74_{-10}^{+16}$ & $32_{-6}^{+8}$ & $-5_{-15}^{+13}$ \\
12 & $1.957_{-0.406}^{+0.326} \times 10^{15}$ & $128_{-2}^{+2}$ & $-11_{-9}^{+4}$ & $7_{-17}^{+14}$ & $-69_{-4}^{+8}$ & $221_{-2}^{+4}$ & $-17_{-6}^{+5}$ \\
22 & $9.250_{-1.817}^{+2.286} \times 10^{14}$ & $302_{-2}^{+3}$ & $-6_{-6}^{+7}$ & $174_{-47}^{+47}$ & $-81_{-7}^{+8}$ & $33_{-2}^{+3}$ & $-7_{-7}^{+7}$ \\
\hline
\end{tabular}

Plunge is positive downwards and negative upwards. Event numbers refer to those in Table 2.

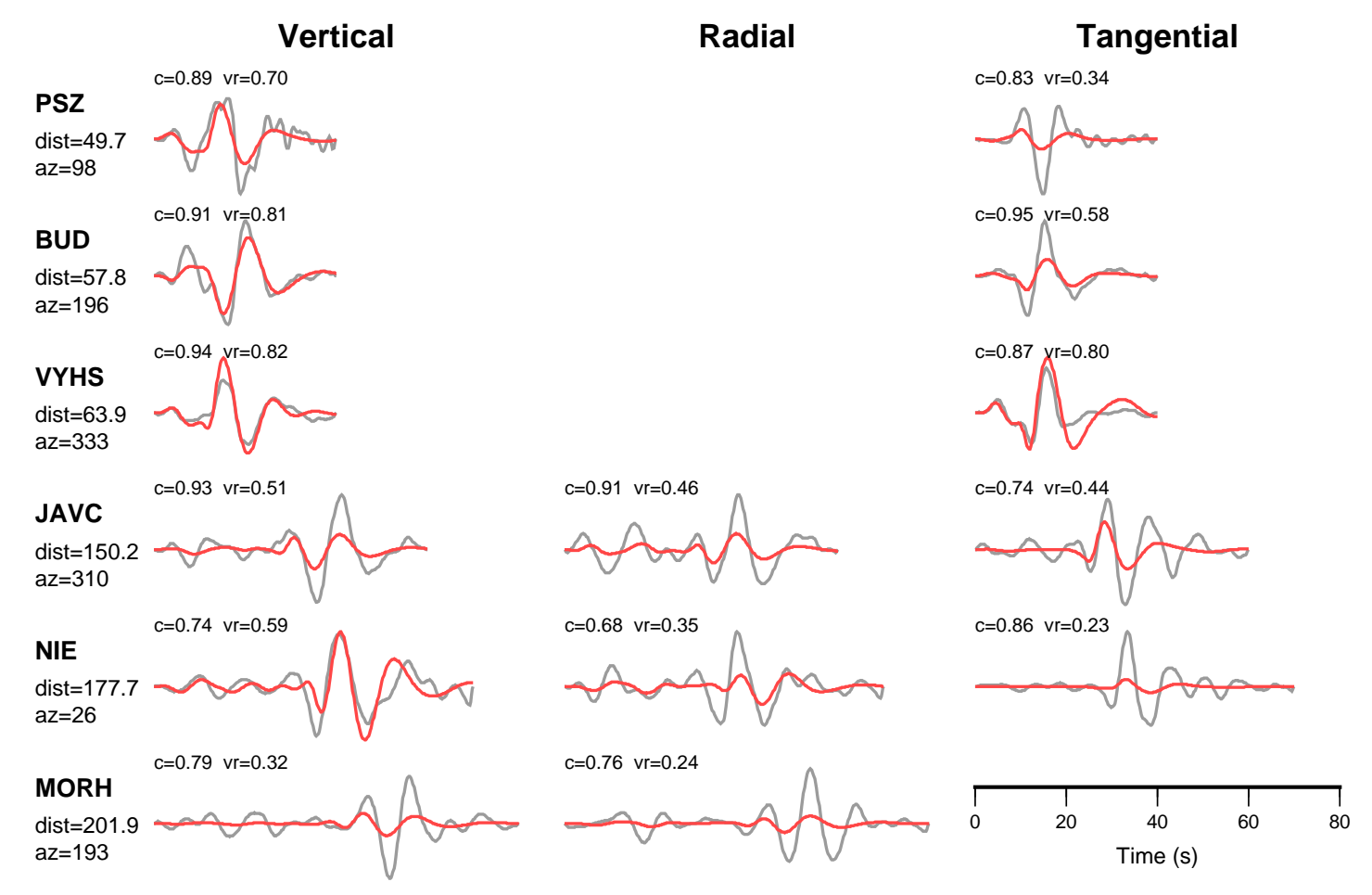

Fig. 6 Waveform comparison for the weakest earthquake analyzed in this study (event 9, $M_{w}=3.6$ ). The observed seismograms (gray lines) are bandpass filtered with cut-off frequencies of 0.05 and $0.125 \mathrm{~Hz}$. The synthetic waveforms (red lines) are computed using the maximum likelihood source parameters obtained by waveform inversion. On the left-hand side of each row, station code, epicentral distance in km (dist), and station azimuth (az) are indicated. The numbers above each waveform represent the normalized correlation (c) and variance reduction (vr). Waveforms are normalized for each station and component individually. 


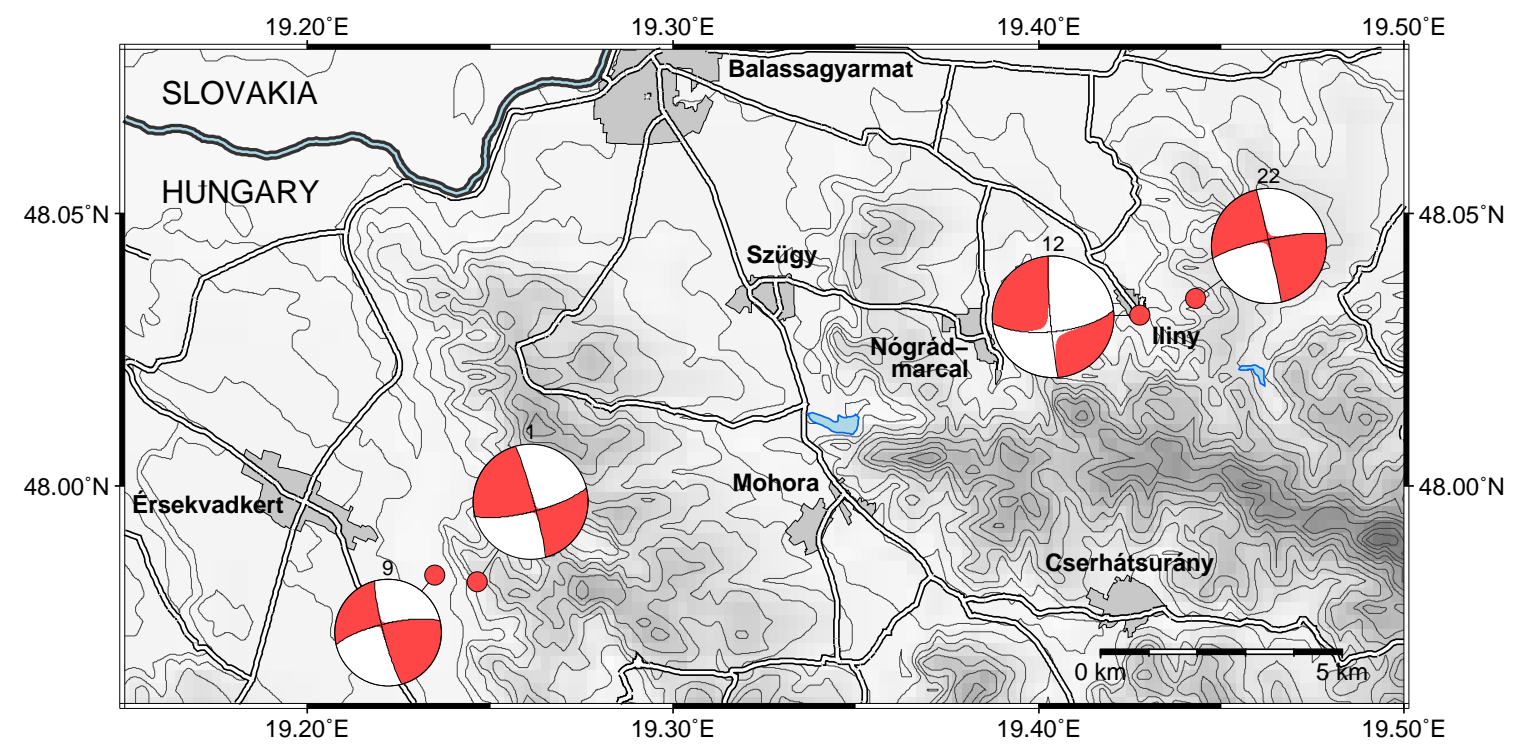

Fig. 7 Source mechanisms of the analyzed earthquakes on a map of the source area. Beach ball size is proportional to event magnitude (shaded area: compression; open area: dilatation). Equal area projection of lower hemisphere is used. Event numbers above the beach balls refer to those in Table 2.

Geological Survey National Earthquake Information Center (USGS NEIC) and the German Research Centre for Geosciences (GFZ), regional moment tensor solutions have also been published for the two $M_{L}>4$ events. All these previous moment tensor solutions show very good agreement with the source mechanisms retrieved in this study (Fig. 5, Table 3).

To quantitatively compare our solutions to those mentioned above, we follow Pasyanos et al. (1996) using their moment tensor difference parameter $\mu$ defined as the root mean square of the differences of the moment tensor elements normalized by their respective scalar moment. Focal mechanisms with $\mu<0.25$ are essentially the same but start to diverge for $0.25<\mu<0.50$, whereas $\mu>0.50$ indicates significantly different mechanisms.

As seen from Table 3, the solutions obtained by Wéber (2016) are practically identical to ours $(\mu \leq 0.01)$. Considering the inversion frequency band and the small differences between the a priori hypocenters used in the waveform inversion procedure, this result is not surprising at all. Consequently, our observations are essentially the same as those reported by Wéber (2016). For event 12, the USGS NEIC mechanism differs only slightly from the solution of this study $(\mu=0.28)$. Indeed, both mechanisms agree equally well with the available clear readings of first-arrival P-wave polarities (Fig. 5). For event 1, the difference between the GFZ mechanism and our result is more pronounced $(\mu=$ 0.36 ). Both the strike and the dip of the GFZ solution differ from those obtained in this research. We consider our solution to be better, however, as it better agrees with the first-arrival P-wave polarities (Fig. 5).
To illustrate the achieved quality of waveform fitting, Fig. 6 compares the observed seismograms of event $9\left(M_{w}=\right.$ 3.6) and the synthetic waveforms computed using the best (maximum likelihood) source parameters. Two quantities are given for each seismogram: the normalized correlation coefficient $c$ and the variance reduction $v r=1-\sum_{i} r_{i}^{2} / \sum_{i} d_{i}^{2}$, where $r_{i}$ and $d_{i}$ are samples of the residual vector and the data vector, respectively. The resulting correlation values are mostly above 0.8 indicating that the synthetics and the data usually correlate satisfactorily. The achieved variance reduction values, however, show that the observed waveform amplitudes are not always modeled very well. Nevertheless, we obtained acceptable waveform matching.

In Fig. 7 we summarize our source mechanism solutions on a map of the source area.

\section{Discussions and conclusions}

In this paper we analyzed all seismic data available to us for the 2013-2015 Nógrád sequence in order to estimate the source parameters of the detected earthquakes.

Using the Bayesloc multiple-event location algorithm, we have succeeded in determining the hypocenters of 30 earthquakes with local magnitude ranging from 1.5 to 4.2 . The events occurred in two small regions of a few squared kilometers: one to the east of Érsekvadkert and the other at Iliny (Fig. 2). The uncertainty of the epicenters is about 1.5$1.7 \mathrm{~km}$ in the E-W direction and $1.8-2.1 \mathrm{~km}$ in the N-S direction at the $95 \%$ confidence level. The estimated event depths are confined to the upper $3 \mathrm{~km}$ of the crust. 
We have successfully estimated the full moment tensors of $4 M_{w} \geq 3.6$ earthquakes using a probabilistic waveform inversion procedure. The non-DC components of the retrieved moment tensor solutions are statistically insignificant. The negligible amount of the ISO component implies the tectonic nature of the investigated events. The obtained centroids (Table 3 ) differ from the hypocenters (Table 2) just within the calculated location errors.

The moment tensor solutions displayed in Figs 4 and 7 reveal that both the $\mathrm{P}$ and $\mathrm{T}$ principal axes are horizontal, and the $\mathrm{P}$ axis is oriented along a NE-SW direction. According to the classification scheme of Zoback (1992), all of the investigated earthquakes have strike-slip mechanism with either right-lateral slip on an approximately N-S striking, or leftlateral movement on a roughly E-W striking nodal plane.

Bada et al. (2007) presented a compilation of data on the present-day stress pattern in the Pannonian basin and constructed the trajectories of maximum horizontal stress directions (Fig. 1). In the Nógrád region, Bada et al. (2007) suggest an approximately NE-SW striking maximum horizontal stress direction. The $\mathrm{P}$ axes of the moment tensors retrieved in this study are also oriented along a roughly NE-SW direction $\left(31^{\circ}<\right.$ azimuth $\left.<41^{\circ}\right)$. Thus, the orientations of the obtained focal mechanisms are in good agreement with the present-day stress field derived by Bada et al. (2007).

The Nógrád earthquake sequence occurred on subfaults of the Rába-Hurbanovo-Diósjenő fault zone (Fig 1). We hope that the results of the presented research can help to better understand the otherwise little-known small-scale tectonic structure of the source area.

Acknowledgements The author would like to thank the different organizations that operate seismological networks in the neighboring countries of Hungary for making their high quality data available. Figures were prepared using the Generic Mapping Tools software (Wessel and Smith, 1998).

\section{References}

Bada G, Horváth F, Dövényi P, Szafián P, Windhoffer G, Cloetingh S (2007) Present-day stress field and tectonic inversion in the Pannonian basin. Global and Planetary Change 58:165-180.

Crotwell HP, Owens TJ, Ritsema J (1999) The TauP Toolkit: Flexible seismic travel-time and ray-path utilities. Seismol Res Lett 70:154-160.

Gráczer Z, Wéber Z (2012) One-dimensional P-wave velocity model for the territory of Hungary from local earthquake data. Acta Geod Geoph Hung 47:344-357. doi: 10.1556/AGeod.47.2012.3.5

Hanks TC, Kanamori H (1979) A moment-magnitude scale. J Geophys Res 84:2348-2350.
Herrmann RB (2013) Computer programs in seismology: An evolving tool for instruction and research. Seism Res Lett 84:1081-1088. doi: 10.1785/0220110096

Herrmann RB, Wang CY (1985) A comparison of synthetic seismograms. Bull Seismol Soc Am 75:41-56.

Horváth F, Bada G, Windhoffer G, Csontos L, Dombrádi E, Dövényi P, Fodor L, Grenerczy Gy, Síkhegyi F, Szafián P, Székely B, Timár G, Tóth L, Tóth T (2006) Atlas of the present-day geodynamics of the Pannonian Basin: Euroconform maps with explanatory text. Magyar Geofizika 47:133-137 (in Hungarian with English abstract).

Jost ML, Herrmann RB (1989) A student's guide to and review of moment tensors. Seism Res Lett 60:37-57.

Lomax A, Curtis A (2001) Fast, probabilistic earthquake location in 3D models using oct-tree importance sampling. Geophys Res Abstr 3:955.

Myers SC, Johannesson G, Hanley W (2007) A Bayesian hierarchical method for multiple-event seismic location. Geophys J Int 171:1049-1063. doi: 10.1111/j.1365246X.2007.03555.X

Myers SC, Johannesson G, Hanley W (2009) Incorporation of probabilistic seismic phase labels into a Bayesian multiple-event seismic locator. Geophys J Int 177:193204. doi: 10.1111/j.1365-246X.2008.04070.x

Pasyanos ME, Dreger DS, Romanowicz B (1996) Toward real-time estimation of regional moment tensors. Bull Seismol Soc Am 86:1255-1269.

Riedesel MA, Jordan TH (1989) Display and assessment of seismic moment tensors. Bull Seismol Soc Am 79:85100.

Rubinstein RY, Kroese DP (2008) Simulation and the Monte Carlo Method. John Wiley \& Sons, Hoboken, New Jersey. Sipkin SA (1993) Display and assessment of earthquake focal mechanisms by vector representation. Bull Seismol Soc Am 83:1871-1880.

Wang CY, Herrmann RB (1980) A numerical study of P-, SV-, and SH-wave generation in a plane layered medium. Bull Seismol Soc Am 70:1015-1036.

Wéber Z (2006) Probabilistic local waveform inversion for moment tensor and hypocentral location. Geophys J Int 165:607-621. doi: 10.1111/j.1365-246X.2006.02934.X

Wéber Z (2009) Estimating source time function and moment tensor from moment tensor rate functions by constrained L1 norm minimization. Geophys J Int 178:889900. doi: 10.1111/j.1365-246X.2009.04202.x

Wéber Z (2016) Probabilistic waveform inversion for 22 earthquake moment tensors in Hungary: new constraints on the tectonic stress pattern inside the Pannonian basin. Geophys J Int 204:236-249. doi: 10.1093/gji/ggv446

Wéber Z, Süle B (2014) Source properties of the 29 January 2011 ML 4.5 Oroszlány (Hungary) mainshock and its aftershocks. Bull Seismol Soc Am 104:113-127. doi: 10.1785/0120130152 
Wessel P, Smith WHF (1998) New, improved version of generic mapping tools released. EOS Trans Am Geophys Un 79:579.

Zoback ML (1992) First and second order patterns of stress in the lithosphere: the World Stress Map Project. J Geophys Res 97:11703-11728.

Zsíros T (2000) Seismicity and Seismic Hazard in the Carpathian Basin: Hungarian Earthquake Catalog (4561995). MTA FKK GGKI, Budapest (in Hungarian). 